\title{
A Proposed Holistic Approach to the Critical Analysis of Online News Reports
}

\author{
Raith Zeher Abid ${ }^{1} \&$ Nidaa Hussain Fahmi Al Khazraji ${ }^{1}$ \\ ${ }^{1}$ English Language Department, College of Education for Human Sciences, University of Karbala, Iraq \\ Correspondence: Raith Zeher Abid, English Language Department, College of Education for Human Sciences, \\ University of Karbala, Iraq. E-mail: raithzeher@gmail.com; nidaa62@gmail.com
}

\author{
Received: October 27, 2017 Accepted: November 18, 2017 Online Published: December 23, 2017 \\ doi:10.5539/ijel.v8n2p222 URL: http://doi.org/10.5539/ijel.v8n2p222
}

\begin{abstract}
This study proposes a new holistic approach that accounts for the multi-layered structure of online news reports. The approach consists of two phases of analysis. The journalistic phase examines the headline, semiotics, and text of the report while the societal reception phase examines the comments that readers make as a response to the news report. Consequently, unlike previous frameworks of CDA, this approach finds a balance between the analysis of discourse production and discourse reception. To demonstrate the approach, we analysed an online news report from CNN about the Saudi ban on women to drive. The analysis shows that although the journalistic phase focuses on the courageous acts of Saudi women who are defying the ban to achieve equality in Saudi Arabia, the societal reception phase results are characterised by racist discourse against Islam and Muslims in general.
\end{abstract}

Keywords: online news reports, CDA, production level, reception level

\section{Introduction}

Media, in general, are perceived as fundamental institutions whose influence is gradually replacing other central institutions in society, including the church (Talbot, 2007). This is emphasised by Macdonald (2003, p. 1) who states that "the media still figure strongly as narrative-makers, capable of influencing public perceptions of a "reality"" to the point that it can be more influential than politicians' thoughts and other opinion-formers. The media are perceived conventionally as a "broad term which can refer to a totality of how reality is represented in broadcast and printed media from television to newspaper" (O'Keeffe, 2006, p. 1). Van Dijk (2006) emphasises the importance of media discourse as a source via which the knowledge of a community manifests itself in its discourse that is directed at the public as a whole. This is because the shared knowledge of a society and what its members consider as "real, interesting, beautiful, moral and all the other meanings they attach to the world-is partly constructed by each member and partly by institutions such as newspapers or radio stations" (Matheson, 2005, p. 1).

The recent technological advances that the world witnessed and is still witnessing have created two types of media which are mass media and new media. Mass media, as in TV and newsprint, according to Curran (1991), is viewed in terms of three paradigms, Marxist, Liberal-Pluralist, and Radical Democratic. The Marxist paradigm emphasizes that powerful groups in society control media to suite their purposes. Consequently, journalists are viewed as a mean to integrate the ideals and norms of the elite groups. The Liberal-Pluralist paradigm highlights the idea that mass media operate with considerable autonomy and the state only intervenes to help the public interest. The Radical Democratic paradigm states that although mass media, to some extent, are in favour of the elite, it does not make it completely susceptible to those powerful groups. The most relevant paradigm to the critical analysis of discourse is the Radical Democratic paradigm because critical analysis studies do not only focus on media's biased point of view towards social actors, but also on cases in which media defy norm practices and support the oppressed and the misrepresented. The influence of mass media on the public is extraordinary because they have the capacity to outline cultures and the information that are available to the public to the point that even "dressing, talking, and even thinking have likely to be shaped by the media" (Anderson \& Taylor, 2011, p. 42). However, as more people are now using the internet to read and watch online the most recent news for free, the popularity of mass media in the public is, to some extent, challenged (Salman et al., 2011). The media resulted from these recent technological advances is now perceived as new media. The 
basic technical comprehension of new media is that they are programmable and numerical, thus, their content can be mathematically represented and manipulated by using various computer algorithms (Manovich, 2001). This resulted in new media to take several manifestations that include online news reports, blogs, and so on. Although new media will not completely replace traditional mass media, it will "certainly and markedly reduce and limit those previous media, much as the invention of aviation did to land and sea transportation" (Crosbie, 2002, p. 7).

One of the crucial differences between mass media and new media is interactivity. To mass media, interactivity is perceived to be a mediated quasi-interaction (one-way interaction) which is described as "a communicative interaction in mass communication-books, newspapers, radio, television-where the co-involvement of large numbers of spatial and temporally dispersed people is added to the time-space distantiation of mediated interaction" (Chouliaraki \& Fairclough, 1999, p. 43). Consequently, in the situation of a TV programme, the only interaction that can occur between the programme and the recipient is initiated if the recipient wants to turn on the TV, keep it switched on and watch the programme, change the channel, or switch off the TV (Thompson, 1995). However, in the new media, which is digitally oriented, interactivity is based on a two-way interaction which is depicted as a beneficial form of communication that "stresses the great importance of feedback and constant interaction" and creates a context in which "the negotiation of meaning is vitally important" (Fielding, 2006, p. 24). In this context of new media, and specifically online media news reports, the media consumer has the capacity to choose the topic he/she wants to read, ask the writer of the article for information, and comment about the journalist's article. Moreover, the recipient can also be further involved in some websites of aid organisations, as in International Rescue Committee (IRC), by donating money to be a part of the aid efforts. Hence, instead of being a passive receiver of information, the recipient has the capacity to partake in different ways.

Because media, in general, is an influential institution in society, several critical discourse analysis (CDA) studies were conducted to examine critically the depiction of social actors and phenomena in media. Nonetheless, as influential and revolutionary new media is, there has been no approach devised by CDA analysts to account for the complexities of the online news reports because new media is treated similarly to mass media. Consequently, we will propose a new framework to the analysis of online media news reports that will account for the writers' perspective as well as the commenters' point of view. Furthermore, to demonstrate the stages of the framework, a CNN story about the Saudi government prohibition of women drivers will be analysed.

\section{Critical Discourse Analysis}

CDA, Wodak (2001) states, emerged as a network of scholars in the early 1990s in Amsterdam where a symposium was held in January 1991. CDA is revolutionised by researchers that include Norman Fairclough, Teun Van Dijk, Theo Van Leeuwen, Gunther Kress and Ruth Wodak. These researchers formulated their own diverse approaches to the critical analysis of discourse which illuminates CDA's lack of theoretical and methodological unity. This newly formed field of critical discourse analysis is originally based on the framework of critical linguistics. Critical linguistics is designed to uncover the manifestation of ideology in the grammatical and the semantic forms of written discourse and how these forms of discourse formulate meaning and categorise entities, social actors, and happenings (Simpson \& Mayr, 2009). As popular and effective critical linguistics is, it consists of several drawbacks. According to Fairclough (1992), critical linguistics pays little attention to the processes of interpretation as it places too much emphasis on the text as a product. An additional limitation of critical linguistics is that it perceives discourse as an entity with a one-sided effect on reproduction of relations and structures that exist in society while abandoning both "discourse as a domain in which social struggles take place, and change in discourse as a dimension of wider social and cultural change" (Fairclough, 1992, pp. 28-29). Furthermore, the interface between language and ideology is narrowly perceived in critical linguistics as it focuses on vocabulary and grammar, while it neglects aspects in discourse, as in the general narrative and argumentative structures. Critical linguistics focuses solely on written discourse while it ignores spoken discourse. Additionally, critical linguistics focuses heavily on revealing the ideologies in discourse. Hence, this limitation, along with the neglect of the interpretation processes, resulted in critical linguistics to exclude the notion of "sense" which refers to the discourse interpreter's assumptions that are non-existent in text and might be ideological in nature (Fairclough, 1992, p. 29).

CDA is designed to eliminate all these shortcomings in the theoretical framework of its precursor critical linguistics by achieving a "more explicit dialogue between social theory and practice, richer contextualisation, greater interdisciplinarity and greater attention to the multimodality of discourse" (Van Leeuwen, 2006, p. 168). The notion of being critical in CDA symbolises the idea of going beyond the mere description of linguistic features of discourse to also include how and why these features are utilised by the discourse maker (Simpson \& 
Mayr, 2009). This criticalness also implies that CDA analyses diverse genres of discourse that include news articles, political speeches, advertisements, interviews, counselling sessions, and other genres of discourse that predispose unequal relations (Simpson \& Mayr, 2009). CDA perceives the notion of discourse (spoken and written) as a vessel via which aspects of power and ideology are manifested and reproduced to maintain and facilitate dominance, prejudice, and subjugation of minority groups and the powerless in society. Hence, CDA is defined as the analysis of "opaque as well as transparent structural relationships of dominance, discrimination, power and control as manifested in language" (Wodak, 2001, p. 2). One of CDA's fundamental characteristics is its heterogeneous approaches that can be used by researchers.

Several approaches of CDA emphasise their analysis on the reader's perception of the examined discourse, for instance, Van Dijk's (1998) socio-cognitive approach examines the reception level of the mental and societal factors, contexts, limitations, or effects of textual structures and Fairclough's (1992) three dimensional framework examines the processes of interpretation that interrelates the words in the text to the social world. Examining audience reception has been an integral part of communication studies for almost three decades. The main premise of the theory is to examine the responses of the public and audiences by administrating questionnaires and conducting interviews (Bielby \& Harrington, 2008). However, in CDA studies, the general societal perception of discourse is typically measured through the writer's or speaker's own discourse rather than evaluating the actual point view of the readers. This shortcoming deems discourse (written or spoken) as a representative of the overall societal view towards the social actor or phenomenon. This is also emphasised by Pennycook (2001) who states that, although, for example, the prevalent approach of Fairclough's (1992) three dimensional framework accounts in its analysis the production and consumption of discourse, an imbalance always exists because the framework focuses heavily on the analysis of the text to derive the ideologies. Hence, CDA frameworks generally give a "predominant focus on production rather than reception" (Pennycook, 2001, p. 82). Furthermore, based on the audience reception theory, to examine the reception level in the various approaches of CDA, interviews and/or questionnaires should be used (Baker \& Ellece, 2011). However, in the current form of online news reports, we believe that the comments that were made by the readers as a response to the text can be used to examine the reception level. Consequently, the present approach addresses CDA frameworks' limitation of reception level analysis by not only examining the discourse of the writer, but also the discourse of the online commenters who, as a reaction to what they have read, express their own point of view. The following section will explain this study's approach.

\section{The Proposed Holistic Approach}

Although there are several genres of discourse, this approach only focuses on the online media news reports as most influential media outlets have a website. Furthermore, the majority of the population is now reading the news online which resulted in the continuous and drastic decline of printed newspapers (Graham, 2010; Papandrea \& Ricketson, 2014; Geer et al., 2015). The phases of this approach are all oriented to complement the structure of online news reports.

In almost every online news report, there is a headline, a picture(s) that reflects the story, the text of the report, and the comment section at the end of the report. Hence, this approach comprises two main dimensions of analysis, the journalistic dimension and the societal dimension. The former examines the headline of the report, the semiotic features of the report, and the text of the report; while the latter examines the linguistic features of the commenters' views about the report. Consequently, this approach will not only capture the stance of the report writer, but also the stance of the readers who wrote their comments as a reaction to the news article. This approach is clearly depicted in the following figure.

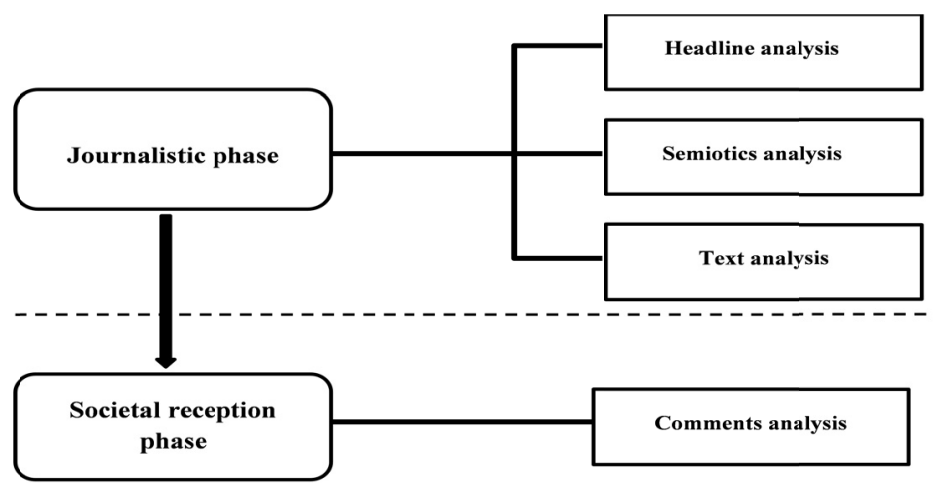

Figure 1. Holistic approach to the critical analysis of the online media news reports 
As mentioned above, this approach consists of two phases, the journalistic phase and the societal reception phase. The journalistic phase consists of headline analysis, semiotics analysis, and text analysis. In the analysis of headlines, researchers can use one of the several frameworks that focus its examination on the various linguistic aspects of headlines, most notably Reah's (2002) framework of headline analysis. However, regardless of the theory used, the analysis should account for the lexical choices as well as the phrasal or clausal patterns of the headline because headlines can be phrases and clauses. Semiotics analysis focuses on the various images that the report includes below the headline or/and within the text of the article itself. In the analysis of the report text, researchers are free to choose any CDA framework(s) of discourse analysis that suites the purpose of their research.

The societal reception phase of the analysis examines critically the comments of the internet users who posted their comments as a response to the online newspaper report. This phase is integral because online news commenters as audience provide "links across, relations among people and media at all levels from the macroeconomic/cultural to the individual/psychological" (Livingstone, 2002: p.251). Hence, it is crucial to emphasise that the same framework(s) that is used in the text analysis should also be used in the comments analysis to compare the stances of the text and the comments. This is because the text and the comments might differ in their ideologies and stances towards social actors and phenomena.

It is essential to note that this approach does not limit the researcher with its own analysis tools because we believe that since the formulation of CDA, virtually every linguistic feature that discourse might include is listed in the various frameworks of CDA. Hence, researchers might choose for their discourse analysis, for example, Fairclough's (1992) three dimensional framework, Van Dijk's (1998) socio-cognitive approach, Van Leeuwen's (2008) representation of social actors theory, or Wodak's (2001) discourse-historical approach. Furthermore, in the frameworks that capture the reception of discourse in society, as in Fairclough's (1992) three dimensional framework \& Van Dijk's (1998) socio-cognitive approach, the holistic approach to the critical analysis of the online media news reports is more suitable as this dimension of analysis can be studied through the use of the online user's comments which capture the readers' views.

\section{The Case Study}

To demonstrate the holistic approach to the critical analysis of the online media news reports, we chose the analysis of a CNN report that discusses the illegality of Saudi women to drive in Saudi Arabia. The article is especially relevant to this study because it received over 2000 comments from the 24th of October 2013 to 1 st of November 2013. The comments were structured in a sequential order from the most recent to the oldest.

The overall structure of the article includes a title, a text, and comments. Although there are no pictures in the article except for video posts of Saudi women defying the ban and driving in Saudi Arabia, this form of multimedia can still be perceived as images because video posts resemble pictures with the exception of a play button in the centre. For the analysis of this case study report, we chose Van Leeuwen's social actor theory because it can be used to analyse the headline, text, comments, as well as the semiotics part. In the analysis of the headline, text, and comments, we will focus on activation, differentiation, evaluative adjectives, and indetermination as they are most relevant to our analysis. The following sections will examine every section in the report because all dimensions of each phase should be analysed so that a holistic comprehension of the online news report is achieved.

\subsection{The Journalistic Phase}

\subsubsection{Headline Analysis}

The chosen report is entitled "Give Saudi Women the Right to Drive". Syntactically, the headline is an imperative sentence that performs the act of commanding other social actors. There are three social actors in the headline. One social actor is included while two are excluded. The included social actor is represented by "Saudi women". The excluded social actors represent the one who is performing the imperative act of ordering as well as the social actor who is being ordered. The social actor who is giving the order is strategically excluded so that it can unanimously represent anyone who disagrees with Saudi Arabia's discriminative rules towards women. The social actor that is being ordered depicts the Saudi officials who still refuse to allow women to drive. Based on the headline, Saudi officials are depicted unfavourably because of their discriminatory assertiveness to refuse the Saudi women the right to drive.

\subsubsection{Semiotics Analysis}

Van Leeuwen's (2008) theory of social actors examines the semiotic aspects of discourse through asking two main questions, "How are people depicted?" as well as "How are the depicted people related to the viewer?" (p. 
137). The former examines the image in terms of social distance, social relation, and social interaction while the latter studies social actors in terms of exclusion, roles, specific and generic, individuals and groups, and categorization. The two images that the article uses are displayed below.

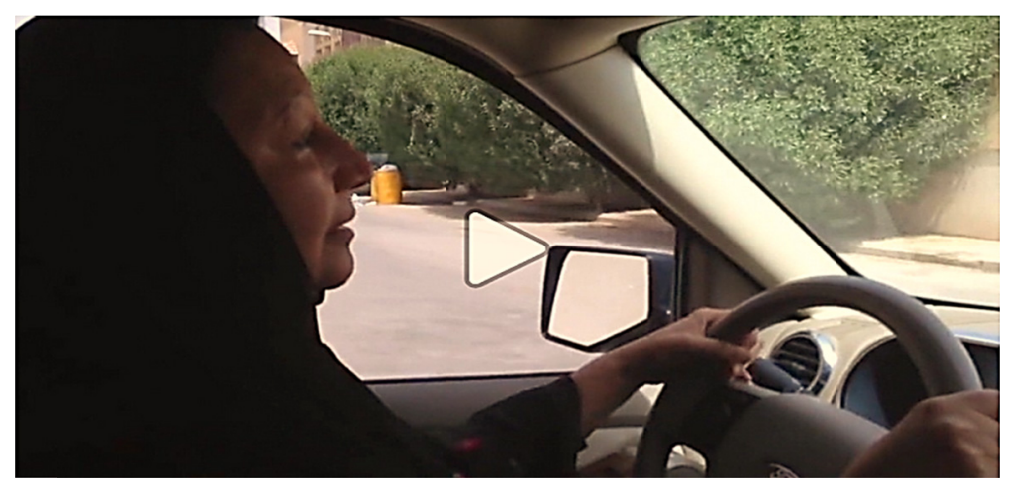

Figure 2. Image shows Saudi woman driving in Saudi Arabia (CNN, October 24 2013)

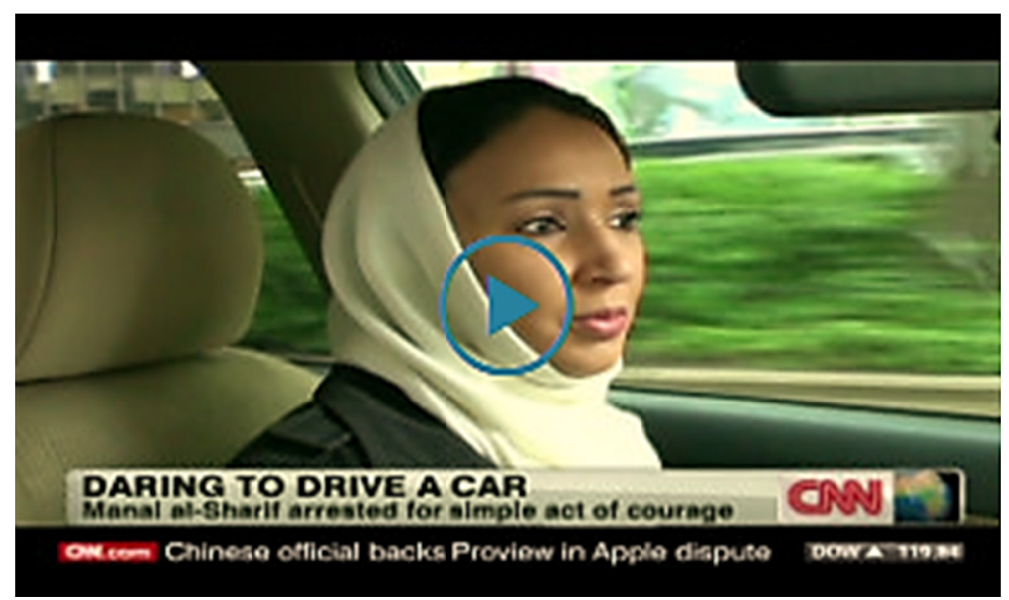

Figure 3. Image shows Saudi woman driving in Saudi Arabia (CNN, October 24 2013)

In the analysis of the way people are depicted, in terms of social distance, the images depict closely Saudi women who are driving their cars in Saudi Arabia. This rendering portrays the closeness of Saudi women, who are struggling to gain their basic rights, to the international readers who are assumed to support their courageous defiance. The analysis of social relation indicates that Saudi women are represented in eye level with the reader to depict their equality with the readers. The examination of social interaction shows that Saudi women are not gazing at the viewer because their act of driving constricts the existence of the eye contact with the reader. Although Van Leeuwen (2008, p. 140) states that when images do not depict people looking at the readers, the image, as a result, forms a "spectacle for our dispassionate scrutiny". In the context of this research, the images positively represent to the reader a spectacle of the courageous defiance of Saudi women to the discriminatory rules of their government.

The analysis of the way people are depicted in relation to the viewer indicate that there is no exclusion in the pictures as the Saudi women who are defying the ban are clearly depicted in the images. With regard to the role, Saudi women are always depicted in the picture to be the dynamic social actor who is steering their vehicles in the streets of Saudi Arabia. Saudi women in the two images are specified as well as represented as individuals who are endeavouring to attain equality. The examination of categorization indicates that the Saudi women in the images are not wearing the typical Abaya (cloak) which is required by law for females to wear (Ham et al., 2004). The images show that the Saudi women are wearing a Hijab and in the second image, the Saudi woman's hair is partially shown. This rendering of Saudi women depicts them as modern and courageous individuals who are challenging the chauvinistic and repressive rules of their government. 


\subsubsection{Text Analysis}

In the analysis of role allocation, Saudi women are activated as well as backgrounded in the article. Saudi women are represented as dynamic social actors in 11 instances. These instances signify their commendable defiance to the unjust rules of their government towards women, as in sentences 1,2,3,4, and5.

1) Saudi women will once again defy their nation's long-standing driving ban

2) Women are already driving and publishing online videos of themselves in the act

3) Saudi women organized a convoy to drive the streets of Riyadh

4) Saudi women continue to face profound discrimination

5) Saudi women take to the roads again

Saudi women are also represented 14 times as the social actor who is at the receiving end of the injustice that is placed on them by religious groups (as in sentence 6), Saudi officials (as in sentence 7), ruling family (as in sentence 8), and the governmental rules (as in sentence 9 and 10).

6) The Grand Mufti...declared a fatwa, or religious edict, against women driving

7) Officials arrested them and suspended many from their jobs

8) Prince Nayef bin Abdulaziz... issued a decree...banning driving for women.

9) The guardianship system still treats them as legal minors

10) Saudi Arabia issues warning to women drivers

Moreover, in the text, Saudi officials and clerics tend to be backgrounded in the text (as in sentences 11, 12, and 13). However, this strategy is not used in this article to disguise them and present them as guiltless, but rather, as ubiquitously known chauvinistic social actors that have no viable justifications for banning women to drive. This is highlighted in sentence 14 and 15 whereby the Saudi officials and clerics are activated as the ones who are giving "excuses" for banning women to drive.

11) One woman was sentenced to 10 lashes

12) Their male guardians were forced to sign pledges that they would not allow the women to drive again.

13) Saudi blogger detained (for aiding the campaign to allow Saudi women to derive)

14) To explain why women cannot drive, Saudi authorities often use the excuse that "society is not ready."

15) A cleric presented a new excuse to prohibit driving for women: he asserted that driving affects women's ovaries.

The analysis of indetermination shows that the exophoric reference "they" is used in the text three times to present those who are capable of change in society. Thus, it is used in sentences 16 and 17 to represent the Saudi women who are defying the rules of the government, while in sentence 18 , "they" represents the husbands who are forced by the government to control their wife's disorderly behaviour of driving.

16) They declared that starting on June 17, 2011, women with international drivers' licenses should take to the roads.

17) They can work in various sectors without approval from their male guardians.

18) They would not allow the women to drive again.

There is one comparison (sentence 19) that the text makes which highlights the importance of the Saudi women defiance. This association compares Saudi women insubordination of the unjust rules and regulations of Saudi Arabia to Rosa Parks courageous act of refusing to give up her seat in a bus for a white passenger in 1955.

19) It (the ban of driving) has become for Saudi women what a bus seat was to Rosa Parks and other African-Americans in the 1950s.

The analysis of aggregation and specification shows that Saudi women are presented via indefinite quantifiers (as in sentences 20 and 21), names (as in sentence 22), and definite quantifiers (as in sentence 23). These representations are intended to highlight the courage of Saudi women as well as the injustice done to them by the Saudi officials.

20) Scores drove, and many were stopped by traffic police

21) Officials ... suspended many from their jobs 
22) Two leading women's rights activists, Wajeha al-Huwaider and Fawzia al-Oyouni...face imprisonment

23) 47 Saudi women organized a convoy to drive the streets of Riyadh

The analysis of functionalization shows Saudi women are either "activists" or "protesters" to emphasize their stance towards achieving equality.

The prenominal adjectives are used to describe the state of women in Saudi Arabia (as in sentences 24 and 25), the claims of the Saudi clerk (as in sentence 26), and the advances in women rights in Saudi Arabia (as in sentence 27).

24) Saudi women continue to face profound discrimination

25) The guardianship system still treats them (Saudi women) as legal minors

26) This absurd contention (the Saudi Mufti claim) is unsubstantiated

27) Saudi Arabia has made several small advances in women's rights

\subsection{The Societal Reception Phase}

\subsubsection{Comments Analysis}

The overall analysis of the 2066 online news comments indicates that relational (55\%) processes are mentioned significantly more than mental (24\%), material (17\%), and verbal processes $(4 \%) .87 \%$ of the comments use generic references to refer to Islam, Muslims, and Arabs. $38 \%$ of the comments use the exophoric reference "they" to depict Muslims as a benighted individuals, $14 \%$ use such references to depict Muslims as violent, and $33 \%$ use these references to depict Muslims as sexist. Furthermore, $94 \%$ of the comments consisted of statements that are negative to Islam and Muslims while only $4 \%$ are positive statements made by those who are defending Islam. Generally, Islam is represented according to three themes, namely Islam as a benighted religion, Islam as a sexist religion, and Islam as a religion of violence. Although the text of the report mainly focuses on Saudi Arabia and its discriminatory rules against women, the comments of the readers arbitrates Islam, Muslims, and Arabs as being sexists, benighted, and violent. Hence, the focus in the comments section is no longer about Saudi women driving rights but on the perception of Islam and Muslims. Furthermore, only few instances in the comment section focus their criticism on Saudis.

The majority of the activation processes state the notion that Islam is a benighted (sentences 28-33), sexist (sentences 34-36), and violent (sentence 37) religion. Consequently, the most frequent transitivity processes is relational processes to aid in creating judgment by using adjectival phrases, as in example 28 , and noun phrases, as in example 30. A limitednumber of comments focus their views on Saudis as violent, as in sentence 38, and benighted, as in sentence 39 .

28) Islam is crude

29) Muslims are idiots

30) Islam is a backwards disease

31) Islam is such a stupid, demonic, backwards, irrational, perverse, intolerant religion!

32) Muslims are the epitome of stone-age baboons

33) Islam is a cancer on humanity

34) Islam is a religion that is very affraid of women

35) Islam is damaging to women

36) Islam is misogynist, oppressive and totalitarian in nature

37) Islam and Sharia law are genocidal ideologies

38) Saudis have blood on their hands from $9 / 11$

39) Saudis are the most r3tarded idiots

The material processes are implemented in the comments to highlight how Islam and Muslims physically impedes its believers from rational thinking by harming their state of mind (sentences 40-44), the violence they are committing (sentence 45), and their violation of women (sentences 46 and 47). The following examples depict this representation:

40) Islam trumps science and common sense

41) Islam dissolves the human brain on contact 
42) These the same people sending their daughters to Syria for a sexual Jihad

43) these dumb people will die off

44) Islam will melt your brain

45) Muslims kill

46) Islamhas placed gender roles for men and women

47) insecure Muslims abuse women and rob them of their basic human rights

The mental processes focus their representation on the credulous mentality of Muslims who tend to follow without questioning as well as detest the idea of change (as in sentences 48-52). Furthermore, mental processes are also implemented to depict Islam's stance towards women (as in sentence 53).

48) people actually believe such nonsense

49) People afraidof change

50) Islam does not value intelligence in its leaders

51) Muslims hate freedom

52) you people would like to go back to caveman days

53) Islam hate women

The verbal processes in the comments also highlight the benighted characteristic of Islam (sentences 54-56), its violent characteristic (sentence 57), and its negative stance towards women (sentence 58).

54) many crazy people that say many crazy things about everything

55) a lot of crazy people in high positions in this world saying stupid stuff

56) Arabs insist on making a joke of their culture and religion

57) Only Islam calls to kill the other because they're unbelievers

58) Islam says women have $1 / 2$ brain

The majority of the comments use generic references to depict Islam, Muslims, and Arabs for instance:

59) Islam is in a dark age

60) Muslims are the epitome of stone-age baboons

61) Arabs especially the clergy are incestuously bred

62) Muslims are in deep sh**

63) Arabs are nuts

64) Islam may make you nuts

Several comments use the exophoric reference "they" to represent Muslims as benighted, such as sentences 65-67, violent, as in example 68-70, and as sexist, for example sentences 71-73. There are only few instances that signal the reference to Saudi individuals, as in sentences 71 and 72.

65) They are abunch of idi0t savants

66) They still think the world is flat

67) They are morons, are illiterate

68) They tend to arrest first and ask questions later

69) They kill them (enemies) and then eat them raw

70) They will do what they usually do to someone who believes differently.....kill them

71) They area misogynist culture

72) They let the clerics keep women as slaves

73) They rape their women into submission

Differentiation in the collected data only focuses on comparing Islam to Christianity and Judaism, as in sentences 74-77 and contrasting Islam from Christianity, as in sentences 78-80, as well as negatively comparing Islamic characters and beliefs to Christian personalities, as in sentences 81 and 82 . 
74) Christians claim Muslims will burn in hell and Muslims claim Christians will burn in hell

75) Remember the Crusades? ... Christians have done their share of killing in the name of their god.

76) (Muslims) like the Jewish people who beat women for violating dress code

77) Islam, Teatards, Taliban, Radical Christians, RW idiocy,...it just shows they all are from the same mind set

78) Jesus saves.......Muslims kill

79) Islam is 600 years younger than Christianity

80) I know Christians there are never oppressed for their religion (unlike Muslims)

81) They have Sheikh Saleh Al-Loheidan and we have Troy Aiken

82) "if the woman is really raped then she will not get pregnant" US Senator about a year ago (christian btw, for those that think this is just an islamic thing, it is not)

There are several evaluative adjectives that negatively depict Islam and Muslims. Virtually all of these adjectives are used to depict Islam and Muslims as benighted, violent, and sexist, as in "extremist", "intolerant", "Sunni radical", "irrational", "demonic", "totalitarian", "stupid", "archaic", "backwards", "perverse", "new", "crude", "oppressive", "misogynist", "crazy", "fundamentalist", "insecure", "intelligent" (sarcasm), "silly", "peaceful" (sarcasm), "idi0ts", "\$tupid", "Wahhabi", "nuts", "dumb", "good" (sarcasm), "ignorant", "insane", "least intelligent", and "retarded".

\section{Discussion}

The examination of the journalistic phase shows that the three dimensions of headline, semiotics, and text analysis collectively used in the report to positively emphasize the courage of the Saudi women who are defying the chauvinistic societal system of their country so that they can be allowed to drive in Saudi Arabia. It is crucial to emphasize that in this stage of analysis, the journalist only riticizes the rules of Saudi Arabia and its religious clerics who are responsible for providing "excuses" so that women will not be permitted to drive. The report, therefore, does not signal the existence of racism towards Islam or Muslims in general because the focus is only on Saudi Arabia as it is well known to be the only country in the world that does not allow its women to drive (Mills \& Mullany, 2011).

The analysis of the societal reception phase diverges from the journalistic phase completely as racist discourse against Islam and Muslimsis prevalent. Hence, the focus is no longer on Saudi Arabia but on Islam and its followers who are deemed to be benighted, sexist, and violent. Furthermore, the focus is no longer on Saudi women's right to drive, but on the racist view of Islam, Muslims, and Arabs. According to Van Dijk (2009), the notion of race is an abstract mental model that is formulated from ideologically based beliefs that reflect the way a community perceives themselves and others. Hence, racialization is a form of depiction based on a set of stereotypes and assumptions about the other race. The CNN article, therefore, provided its readers an opportunity to insult as well as devalue a religion and its people based on the readers' "system of beliefs that one racial group is biologically, intellectually, or culturally inferior...to another" (Yang, 2000, p. 145). The readers, therefore, arbitrated the majority of Muslims by the negative actions of few Saudis.

What is disturbing is that $\mathrm{CNN}$, in its website, provides the internet user with the Community Guidelines of commenting which, most notably, include the willingness of CNN to remove any post that deals with "obscenities, threats, hate speech, material that's ethnically or racially offensive, abusive comments and spam". Hence, all these offensive words towards Islam and Muslimsare not removed because they are deemed "okay" by the $\mathrm{CNN}$ online commenting monitors.

\section{Conclusion}

The main aim of this study is to formulate a holistic approach to the critical analysis of online news reports that will account for the multiple dimensions of this technologically-based form of journalism. Most of the CDA studies focus on texts analysis, as in Cartner (2009), Hanson-Easey \& Augoustinos (2010), O'Sullivan (2011), Abid et al. (2013), and only few studies focus on the comments, as in Every (2013), Hastie \& Rimmington (2014). This approach, hence, consists of two major phases, the journalistic phase, which examines the headline, semiotics, and text, as well as the social reception phase, which looks at the online comments that are made by the readers of the article. The premise of this approach is to find a balance between the analysis of production and reception dimensions of CDA by not only examining the text of the online news report but also the commenters' reaction to it. This approach does not limit researchers to a specific set of linguistic tools and 
semiotics framework of analysis because the various frameworks of CDA can be used to account for these aspects of discourse. Hence, researchers have the capacity to choose the CDA framework that will suit their purpose.

To demonstrate the effectiveness of the holistic approach to the critical analysis of online news reports, we analysed a text form CNN that discusses Saudi women defying their government to drive in the streets of Saudi Arabia. The results of the journalistic phase and the societal reception phase shows that although the article focused on glorifying the Saudi women who are endeavouring to gain equality despite the restrictive rules of their government, the online commenters used predominantly racist discourse to insult Islam and Muslims in general regardless of the fact that these limitation on women only exist in Saudi Arabia.

Such results can only be divulged through this approach because if we follow other approaches of CDA, the results will be limited to the idea that the journalist is praising Saudi women for their defiance and that the rules of Saudi Arabia are prejudicial to women. Consequently, the researcher would assume that the readers will sympathise with Saudi women and support them in their endeavour of equality. However, the results of societal reception phase indicate that the online commenters differed completely form the stance of the report by predominantly insulting Islam and every Muslim by rendering them benighted, violent, and sexist. Only a small number of comments focused their view on Saudis and expressed their support of Saudi women.

Future studies that examine online news reports with the use of this approach can use corpus linguistics to examine how social actors or phenomenon are represented in the journalistic phase and the societal reception phase. The use of corpus linguistics will insure the use of a representative data as well as results reliability and method replicability. For instance, researchers can examine how journalists of online news reports represent refugees and how the commenters view these refugees. This provides a better understanding of the manner in which refugees are viewed by journalists and society. It is essential to note that all dimensions of each phase should be included so that a holistic comprehension of the online news report is achieved.

\section{References}

Abid, R. Z., Abdul Manan, S., \& Abdul Amir, Z. (2013). "Those nation wreckers are suffering from inferiority complex": The depiction of Chinese miners in the Ghanaian press. International Journal of Society, Culture \& Language, 1, 34-50.

Andersen, M. L., \& Taylor, H. F. (2010). Sociology: The essentials. USA: Wadsworth.

Baker, P., \& Ellece, S. (2011). Key terms in discourse analysis. UK: A \& C Black.

Begum, R. (2013). Give Saudi women the right to drive. CNN. Retrieved from http://edition.cnn.com/2013/10/24/opinion/begum-saudi-women-driving/

Bielby, D. D., \& Harrington, C. L. (2008). Global TV: Exporting television and culture in the world market. New York: New York University Press.

Cartner, J. M. (2009). Representing the Refugee: Rhetoric, discourse and the public agenda. (Doctoral dissertation). Retrieved from University of Notre Dame Australia ResearchOnline@ND.

Chouliaraki, L., \& Fairclough, N. (1999). Discourse in late modernity: Rethinking critical discourse analysis. Edinburgh, UK: Edinburgh University Press Ltd.

Crosbie, V. (2002). What is new media? Retrieved from http://www.sociology.org.uk/as4mm3a.doc

Curran, J. (1991). Rethinking the media as a public sphere. In P. Dahlgreen \& C. Sparks (Eds.), Communication and citizenship: Journalism and the public sphere in the new media age (pp. 27-57). London, UK: Routledge.

Every, D. (2013). "Shame on you": The language, practice and consequences of shame and shaming in asylum seeker advocacy. Discourse \& Society, 24, 667-686. https://doi.org/10.1177/0957926513486223

Fairclough, N. (1992). Discourse and social change. Cambridge, UK: Polity Press.

Fielding, M. (2006). Effective communication in organisations. South Africa: Distinct Communication.

Geer, J. G., Schiller, W. J., Herrera, R., \& Segal, J. A. (2015). Gateways to democracy: An introduction to American government. Boston, USA: Cengage Learning.

Graham, G. (2010). The role of the internet in the decline and future of regional newspapers. In T. J. Strader (Ed.), Digital product management, technology and practice: Interdisciplinary perspectives (pp. 142-153). USA: IGI Global. 
Hanson-Easey, S., \& Augoustinos, M. (2010). Out of Africa: Accounting for refugee policy and the language of causal attribution. Discourse \& Society, 21, 295-323. https://doi.org/10.1177/0957926509360744

Hastie, B., \& Rimmington, D. (2014). "200 years of white affirmative action": White privilege discourse in discussions of racial inequality. Discourse \& Society, 25, 186-204. https://doi.org/10.1177/0957926513516050

Livingstone, S. (2002). Relationships between media and audiences: Prospects for audience reception studies. In T. Liebes \& J. Curran (Eds.), Media, ritual and identity (pp. 237-255). UK: Taylor and Francis.

Macdonald, M. (2003). Exploring media discourse. UK: Arnold.

Manovich, L. (2001). The language of the new media. Cambridge, USA: The MIT Press.

Matheson, D. (2005). Media discourses: Analysing media texts. USA: Open University Press.

Mills, S., \& Mullany, L. (2011). Language, gender and feminism: Theory, methodology and practice. UK: Taylor $\&$ Francis.

O’Keeffe, A. (2007). Investigating Media Discourse. London, UK: Routledge.

O'Sullivan, N. (2011). Is social inequality perpetuated through media discourse? A critical discourse analysis of representations of ethnicity in the Manchester Evening News. MMU Psychology Journal. Retrieved from http://www.did.stu.mmu.ac.uk/MMUPsychology_Dissertations/2011dissertations/

Papandrea, F., \& Ricketson, M. (2014). Australia: State aid to newspapers-not a priority. In P. C. Murschetz (Ed.), State aid for newspapers: Theories, cases, actions (pp. 115-135). New York, USA: Springer Science \& Business Media.

Pennycook, A. (2001). Critical applied linguistics: A critical introduction. New York, USA: Routledge.

Reah, D. (2002). The language of newspapers. London, UK: Psychology Press.

Salman, A., Ibrahim, F., Yusof, M., Mustaffa, N., \& Mahbob, M. H. (2011). The Impact of New Media on Traditional Mainstream Mass Media. The Innovation Journal: The Public Sector Innovation Journal, 16, $1-11$.

Simpson, P., \& Mayr, A. (2009). Language and power: A resource book for students. London, UK: Routledge.

Talbot, M. (2007). Media discourse: Representation and interaction. Edinburgh, UK: Edinburgh University Press Ltd.

Thompson, J. B. (1995). Media and Modernity: A Social Theory of the Media. Cambridge, UK: Polity Press.

Van Dijk, T. A. (1998). Opinions and ideologies in the press. In A. Bell \& P. Garrett (Eds.), Approaches to media discourse (pp. 21-63). Oxford: Blackwell Publishing.

Van Dijk, T. A. (2006). Ideology and discourse analysis. Journal of Political Ideologies, 11, 115-140. https://doi.org/10.1080/13569310600687908

Van Dijk, T. A. (2009). Society and discourse: How social contexts influence text and talk. Cambridge, UK: Cambridge University Press. https://doi.org/10.1017/CBO9780511575273

Van Leeuwen, T. (2006). Critical Discourse Analysis. In J. L. Mey (Ed.), Concise Encyclopedia of Pragmatics (pp. 166-169). UK: Elsevier. https://doi.org/10.1016/B0-08-044854-2/00501-0

Van Leeuwen, T. (2008). Discourse and Practice. New York: Oxford University Press. https://doi.org/10.1093/acprof:oso/9780195323306.001.0001

Wodak, R. (2001). The discourse-historical approach. In R. Wodak \& M. Meyer (Eds.), Methods of Critical Discourse Analysis (pp. 63-93). UK: Sage.

Wodak, R. (2001). What CDA is about—a summary of its history, important concepts and its developments. In R. Wodak \& M. Meyer (Eds.), Methods of Critical Discourse Analysis (pp. 1-13). UK: Sage.

Yang, P. Q. (2000). Ethnic studies: Issues and approaches. New York, USA: SUNY Press.

\section{Copyrights}

Copyright for this article is retained by the author(s), with first publication rights granted to the journal.

This is an open-access article distributed under the terms and conditions of the Creative Commons Attribution license (http://creativecommons.org/licenses/by/4.0/). 